\title{
RE-WRITING THE CONSTRUCTION HISTORY OF BOUGHTON HOUSE (NORTHAMPTONSHIRE, UK) WITH THE HELP OF DOCU-TOOLS $®$
}

\author{
Jana C. Schuster \\ Faculty of Architecture and Art History, University of Cambridge, 1-5 Scroope Terrace, Cambridge, CB2 1PS \\ jcs97@cam.ac.uk
}

KEY WORDS: Docu-tools ${ }^{\circledR}$, Digital building documentation, Building \& construction-history research, Tablet-based documentation

\begin{abstract}
:
The tablet-based software docu-tools digitize the documentation of buildings, simplifies construction and facility management and the data analysis in building and construction-history research. As a plan-based software, 'pins' can be set to record data (images, audio, text etc.), each data point containing a time and date stamp. Once a pin is set and information recorded, it can never be deleted from the system, creating clear contentious-free documentation. Reports to any/all data recorded can immediately be generated through various templates in order to share, document, analyze and archive the information gathered. The software both digitizes building condition assessment, as well as simplifies the fully documented management and solving of problems and monitoring of a building. Used both in the construction industry and for documenting and analyzing historic buildings, docu-tools is a versatile and flexible tool that has become integral to my work as a building historian working on the conservation and curating of the historic built environment in Europe. I used the software at Boughton House, Northamptonshire, UK, during a one-year research project into the construction history of the building. The details of how docu-tools was used during this project will be discussed in this paper.
\end{abstract}

\subsection{Introduction}

Thorough, precise building documentation is a key aspect of preserving and maintaining buildings, monuments and sites, and for coordinating communication between the people tasked with caring and protecting historic building fabric, tradespeople, users and researchers. Qualitative documentation which can easily be presented as legally admissible evidence of a building's condition at a specific point in its history to assist with settling legal disputes (or for research and other purposes) is of great significance. Anybody involved with buildings - be it in the heritage industry, the construction trade or facility management is aware of the monetary value of thorough building documentation

Regularly documenting a building for whatever purpose has traditionally been an unthankful task, involving systematically gathering and maintaining evidence, followed by hours of report-writing. The scale of these tasks is defined by the level of detail required, the regularity at which a building needs to be inspected and documented, and the complexity of the site. Systematic, detailed documentation is therefore something which often moves to the bottom of one's priorities, but it is exactly this material which becomes of vital significance when problems arise, disasters strike, and proper care and maintenance has to be demonstrated.

Such documentation also has an obvious value to historians, researchers, curators and conservators who can draw conclusions on how something might have looked, been used, or how it was originally created. As building historians, it is our task to combine and comprehend vast quantities of documentary sources and secondary research, together with physical building evidence, and verbal accounts and records of the building at hand. Working on large and intricate sites, analyzing and structuring the sheer quantity of data and information accumulated over often a long period of time into a coherent narrative of a building's evolutionary history can be challenging. Finding a digital tool to make the process of accumulating and analyzing all this data easier is therefore important. Having a digital tool which at the same time can also be used to easily create detailed, transparent documentation that can be quickly transformed into usable reports, providing contentiousfree documentation is of great value to academics and the wider heritage and building industry alike.

Docu-tools is part of an increasing number of programmes and apps available to help with digital building documentation, and construction and facility management; other similar programmes include Skill Software, DefectReader, edr software, conject, Datengut, and some notable differences between them and docutools will be highlighted.

In this paper, I will focus on how I used the software docutools to assist me in my project at Boughton House, after introducing the software more generally. I draw particular attention to its significance for settling legal issues here, which, as will be seen, sets it apart from other programmes currently available to assist with building documentation. Whilst this was not an aspect of the software that was too important for my purposes at Boughton House, it may be of significance for others.

\section{USING DOCU-TOOLS AT BOUGHTON HOUSE}

\subsection{Introducing the project}

For the purpose of my MSt dissertation in Building History at the University of Cambridge (2015/16), I reassessed the architectural history of Boughton House, a country house in Northamptonshire, England. The 
building is listed as Grade I under the British Historic Buildings and Ancient Monuments Act 1953 (list entry number: 10000375) (Historic England, 2017), nestled in 13,000 acres of parks, ancient woods and farm land; it is still privately owned by the Duke of Buccleuch and Queensberry, whose ancestors built the house. The building and its construction history had not been subject of any major, in-depth study since Cornforth (1970-71, 1971, 1992a, 1992b), Heward and Taylor (1996), Heward (1992), and Murdoch (1992). In 2012, the family employed the help of an archivist, Crispin Powell, whose task it has been to catalogue the extensive collection of documents relating to the estates, the family, their buildings and collections, and to make this material accessible for research. The fruits of some of these newly available sources have so far resulted in six $\mathrm{PhD}$ projects (three in collaboration with the University of Leicester, one with the University of Cambridge, one with the University of Edinburgh, and one with the University of Southampton) and numerous MA dissertations, including my MSt and $\mathrm{PhD}$ projects.

The challenge of my project was a common one: analyzing the construction history of a grand building (Figure 1), that had evolved over multiple phases, as efficiently as possible. The second Duke of Montagu's (1692-1749) attempt to establish a coherent dynastic narrative by creating various aesthetically consistent interiors and completing the west front was a particular focus of my study. For this, I drew on the family's archival material, located in multiple record offices and private buildings, much of which was still uncatalogued during my research project, as well as extensively analyzing the building's original fabric.

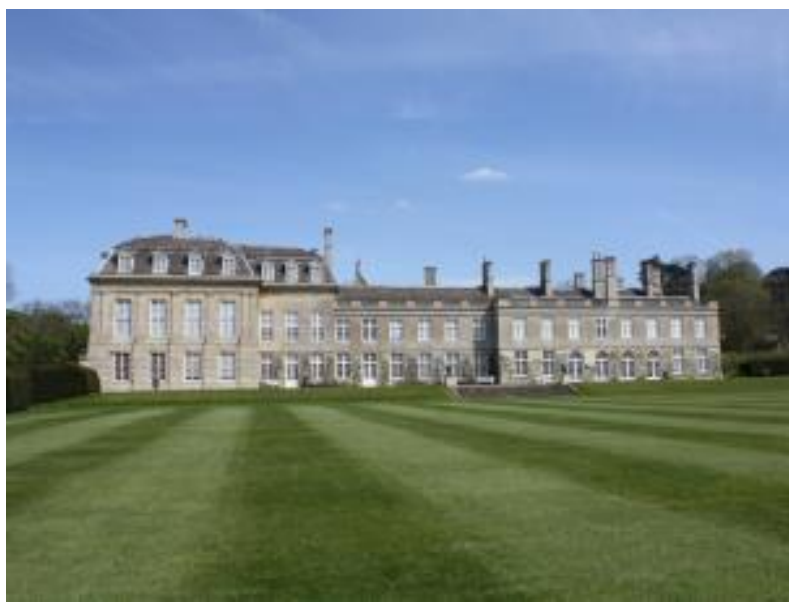

Figure 1 Boughton House. West Elevation @Author

\subsection{Docu-tools}

Before exploring how I used this tool for my research project, I will explain some basic technical points. Docutools is a tablet-based software (iOS and Android) developed in Austria, currently available in 11 languages. The software is plan/image-based, working with jpeg, PDF and DWG/DXF. Different 'pins' are set on the plan/image, and with each pin things can be documented through the tablet by taking photographs, video, audio recording or writing notes on it, and existing data (e.g. wide-angle lens images) can be imported and allocated to a specific pin (Figure 2). The software proposes a collection of different pin categories to clarify right from the outset what you are doing (e.g. recording a defect/damage or conducting an inspection), but these pin categories can also be customized to suit personal needs, and each pin displays its status (open, in progress, done, approved by administrator).

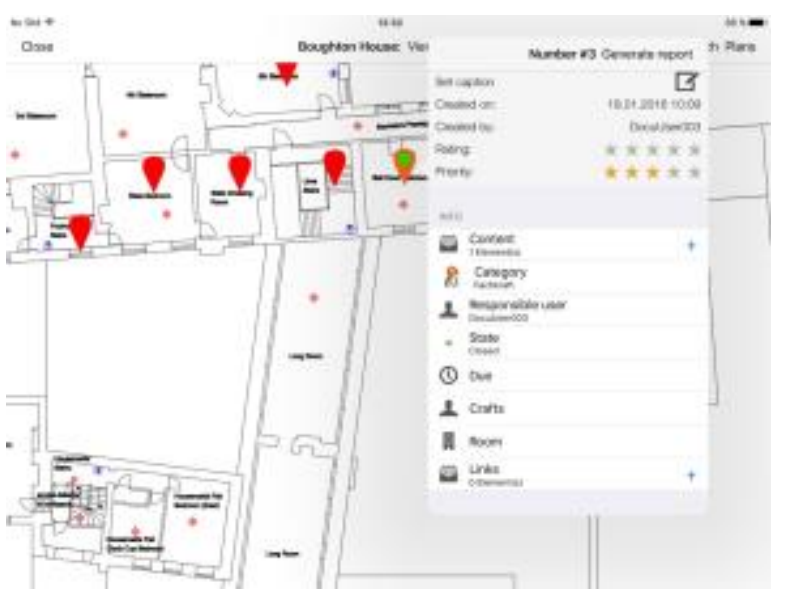

Figure 2 Screenshot of docu-tools. Boughton House project

The software can be set up in different ways to suit the needs of an organization/individual, either with a cloudbase, or installed on a server/PC. It is on these platform that projects are created, plans are imported, pin categories established, and access and user rights set. A project can be allocated to and worked on by multiple tablets at the same time, allowing different people to document separately on the same project. By logging into the app with a username, the software always records who is documenting when and what. All the different tablets synchronize back to the same server/cloud on command. This allows the user to easily communicate what is going on at a site, what has been done, and to set and manage tasks and problems between different people. This is particularly important for larger buildings, projects and organisations.

Significantly, all documentation and recording can be done whilst the tablet is off-line and does not have access to a Wi-Fi network. This means that when you work on a site where there is no $\mathrm{Wi}-\mathrm{Fi}$, which is very common (due to rural locations, construction sites not yet on the grid, not enough data roaming, a basement where the signal does not work etc.) you can still record and document everything properly. Working mostly in country house research where I am glad if we have electricity and central heating, never mind $\mathrm{Wi}-\mathrm{Fi}$, this is an important aspect of the software for me. Once back in a secure network, the tablet can then be synchronized again with the server, thus securing all data recorded.

On the point of data preservation and long-term storage, the difficulty is the same here as for the rest of the digital world: if the server/cloud crashes and no adequate backup system is established, is the data lost? The software has a Report generator on the tablet, with which PDF reports can be created immediately, based on a selection of the different report templates. These reports, like any other PDF file, can be shared, saved to the cloud or any other 
backup system, and printed and filed for archive purposes. All data can also be exported in word and excel files from the server.

The search functions enable the user to interrogate the data in a focused manner, and with the Time Travel feature it is possible to understand past decisions and conditions by directing the search engine to show your project as it was at a specific date and time.

The final but important point to be made here is why from a legal perspective, docu-tools is so far unique. Unlike other digital documentation tools (c.f. Skill Software, DefectReader, edr software, conject, Datengut), with docu-tools, once a pin is set and something is recorded, it is there permanently. It is technically impossible for anybody to ever delete something in this system, not even by contacting the software developers. Pins which have been completed or are no longer relevant can be made invisible on the tablet so plans remain 'clutter-free', but nothing can ever actually be deleted, either on the tablet or the server. The system is programmed to keep track of any alterations, providing a time and date stamp with each action taken and a record of who made any alterations. So, if a mistake has been made in the documentation - and human error of course cannot be avoided - it is always possible to go back to this faulty pin and add another comment/record, correcting any previous mistakes. But the full history of whatever has been recorded is always in the system. Similarly, nothing can therefore be deleted by accident. This is a significant characteristic of the software and is the reason why the Austrian Courts of Justice have recognized documentation evidence presented with docutools in legal disputes as contentious-free documentation (e.g. at the Vienna Skylink project) (Docu-tools, 2016). It is essentially impossible with docu-tools to make something appear as wrongly dated evidence and to tamper with the documentation without being traced. So, for example, if you demonstrate with a docu-tools report a record of your adherence to maintaining and monitoring health \& safety regulations in a building, the report is unlikely to be contested as the time and date stamp of these reports cannot be manually altered or disguised in the software. Whether a building is documented during construction, monitored to allow public access and use, or damage is recorded and repairs documented, having a tool that can be trusted on the authenticity of the documentation is a key feature. For the sake of my project at Boughton House, as will be seen, this feature was of lesser importance to me - using docu-tools to document a building for construction history research, I was less concerned with creating a full report documenting, for example, Boughton's adherence to conservation regulations. However, even in the context of using the app for research purposes this feature proved to be useful, and its significance for digital documentation in the construction and heritage industry is not to be dismissed.

\subsection{Using Docu-Tools for Building History Research}

I will now discuss some of the different ways docu-tools was used in researching the construction history of Boughton House, and what conclusions I drew from working with the software.

Firstly, having all my plans of Boughton House on one portable device is useful. A set of 2013 plans formed the basis of my documentation work on which I set all my pins, being the most accurate and updated set of plans of how Boughton looks and functions today. Over the course of my research, I started gathering every historical plan and drawing of the building I could find in the archives; comparing these different older plans, some of which were undated, with the 2013 plans on the tablet is how I started to decipher the construction phases of the country house. In the app, the plans are divided by floors/levels (Figure 3 ) and for each level I continued adding all the plans I found. One thing which cannot be done with the software is overlapping two different plans on the screen at the same time to, for example, start tracing and directly comparing the differences between a 1742 ground floor plan with the 2013 ground floor plan. Similarly, it is not possible to 'draw' on the plans; the only marks which can be made on the plans are pins. Instead, I would switch between the different plans when comparing specific features and interiors, setting pins with notes and observations on the 2013 plans as I went along. With this, I would walk through Boughton, examining building fabric whilst comparing it to my collection of plans, documenting my observations and conclusions on the app as I went along. Thus, when I was at other times working in the archives or libraries and wanted to remind myself of how precisely some detail looked and what my impressions had been thus far, comparing documentary sources (inventories, estate accounts, letters, visitor accounts, vouchers and receipts by builders and tradesmen) to this, I could do this easily just through the tablet I had with me. For the duration of the research project, I had the fortune to be based in Boughton House for work and thus had generally full access to the building. However, much of my documentary source material was located off-site in public archives and when analyzing thousands of vouchers and building accounts during the documentary research part of my project, it proved to be very useful to be able to refer to the building visually through the tablet. For example, my documentary sources revealed that many of the Tudor interior features like timber paneling, fireplaces and heraldic overmantels which were thought to be original to the house were in fact imported from other family-owned properties in the early $18^{\text {th }}$ century. Discovering the precise location of these recycled interior features in Boughton by comparing visual and documentary evidence on the tablet was key to my project. Thus, I was able to prove the origins of some key interiors which in the $18^{\text {th }}$ century had been made to look like they were part of the original Tudor interiors, redating and re-attributing them in the process.

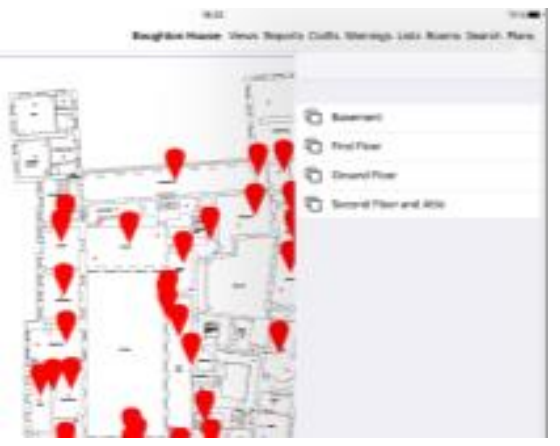

Figure 3 Screenshot of docu-tools. Boughton House project 
This leads to my next point. As mentioned, the app allows the user to create their own pin categories. One of the categories I created was an 'Archive pin'. I exclusively set and used these pins as I was working on primary source material distributed in multiple archives in England. As I would find a bill for, for example, the 'new lime staircase', 1742 , I would then set a pin on the plan at the lime staircase with a reference to the source and what exactly it says (usually transcribing and photographing the document). Thus, over the 10-month research period of this project, working through thousands of vouchers, bills and other documents, all material that clearly referred to the commission, creation or renovation of specific interior and architectural features, I could keep track of the documentation. For any documents found which were clearly of relevance to my project but for which I could not yet immediately identify what precise feature they were talking about - e.g. 'a voucher for the painting of a timber heraldic overmantel in the Long Gallery', when Boughton House has multiple rooms that have historically been referred to as Long Gallery, and numerous fireplaces with a heraldic timber overmantel - then I would deliberately set Archive pins containing this information on the edge of the plan, and not attached to a particular room. This way, I would still collect all data on the plans, and once further evidence had come to light enabling me to identify what precisely the source was detailing, I was able to draw my conclusions, which again would be reflected with a pin.

After completing my archival research, I generated reports with the app for, for example, all my Archive pins relating to the Library, allowing me to easily keep track of and analyze all relevant documentary sources I had been gathering over the past months. With this, the risk of discovering a small but important document and then overlooking it ten months later in my analysis and writeup was reduced. It allowed me to become more efficient and organized about my research notes and discoveries, which ultimately made analyzing and comprehending all my sources into a cohesive narrative of Boughton House's construction history easier and less stressful.

A standard docu-tools pin category is 'Inspection'. I customized this pin to clearly denote with whom I was inspecting the building, usually either my dissertation supervisor Jeremy Musson, or with the Buccleuch archivist Crispin Powell. I would regularly walk through the building with one of them, discussing my discoveries, theories and any queries about particular features and alterations. Documenting the fruits of these inspections by setting pins, often recording our conversations to specific interiors, allowed me to focus on the discussions and not worry about having to accurately document what is being said by also juggling with hand-written notes, a Dictaphone, a camera and a set of plans. For example, I recorded multiple lengthy discussions about the construction history of a puzzling room which had a Chinese staircase with heraldic motifs erected in the mid$18^{\text {th }}$ century that cut into stone arches and a Venetian window which had been built not much earlier, thus creating a very incoherent aesthetic. Having my hands free apart from my tablet, I was able to focus on the purpose and essence of our inspection tours: analyzing and discussing the construction history of this interior in Boughton House. The documentation of these tours happened almost automatically and with the minimum effort and loss of time. Many of these inspections oxxured spontaneously and under time-constraints, but as I just needed my tablet I was always prepared to discuss the intricacies of my research so far, being able to reference relevant documentary sources discovered and recorded with the Archive pins, and to focus on the purpose of each inspection, and ultimately on writing a cohesive dissertation.

If any issues came up during the project, from one of these inspections or whilst studying sources, with the app I could easily and efficiently manage and organize these issues and any tasks arising because of them. For instance, if during one of these inspections I realized I would want to chase up a particular source or reference, or contact somebody for their expert opinion, or to highlight for myself a potential controversy in my analysis I could do this with an 'Alert' pin. For instance, using old inventories to identify the original function of rooms, I discovered later on that one of these inventories followed an a-typical inspection route compared to other inventories, temporarily causing me to draw some inaccurate conclusions and leading to confusion in my analysis. It is possible to give a priority rating to each pin and to set a deadline-alert for the pin and the task it documents. With this, I set and prioritized research tasks and highlighted potential issues, for instance when historic building fabric clearly contradicted original plans, demonstrating that plans are not always executed as drawn, including in the $18^{\text {th }}$ century. Furthermore, based on any issues documented in pins, I could automatically generated reports that outlined the issue, what I had found and concluded so far, and my theories. In situations where I sought the expert opinion on a specific issue these reports could then easily be shared via email, so the person contacted would quickly be able to gage the details of the issue at hand. For example, analyzing the heraldic detailing of a fireplace overmantel - something I was initially not an expert on when I started the project.

\section{CONCLUSION}

I used docu-tools during my project at Boughton House not to document the building, but to assist me in researching and writing my Master's dissertation. I sought to rewrite the architectural and decorative history of the house, particularly for the late $17^{\text {th }}$ and $18^{\text {th }}$ century, in light of substantial newly available documentary evidence, which I was to analyze. In this, docu-tools has been invaluable, allowing me to manage my discoveries and research on a tight schedule of ten months. Working on a building that spans well over a hundred rooms, sprawling over four levels, simply not losing track of where I was in the building and what particular interior scheme I was looking at could be a challenge, especially in the beginning. Being able to visually connect my documentary research in the archives to the plans of Boughton House, photographing the building's every detail as I inspected it continuously, proved of great value. At the same time, an additional benefit of this project and my use of the app has been that upon my completion of the project, I was able to hand over to the Duke and his team not only my dissertation, but also reports detailing and documenting the building as I recorded it over the course of my project, to add to their archives as source material which might be of interest to somebody studying the house and its collection in the future. 
It is no great revelation to anybody with legal experience or dealing with buildings that thorough documentation is incredibly important, both from a historian's perspective (as it is this documentation which allows us to later analyse and study a building) but also from a legal standpoint, as disputes arise. Using the software even in my project context has illustrated for me the advantage of digital documentation and digital solutions to the issues we face in the heritage and building industries. Docutools, originally created to tackle precisely this issue of creating digital documentation that is legally as faultless and airtight as possible, and to help with construction and facility maintenance and management, also proved to be a key tool for building history research. The simplicity of the software interface made these advantages easily apparent, even when building documentation to produce legal records was not my aim in this instance. We are still only somewhat at the beginning of digital documentation, with a proportionately small number of solutions available so far, considering the implications of easy, thorough digital documentation. But in the digital revolution which is undoubtedly happening in this industry, as it is in others, docu-tools makes a strong contribution to the collection of other programmes available for building documentation and management.

\section{ACKNOWLEDGEMENTS}

I thank Sustain Solutions for sponsoring my use of docutools, and Prof. Dr. Matthias Rant for his personal support enabling me to come to the 2017 CIPA conference. This paper is based on my experience and methodology during my MSt dissertation research project (2015/16), undertaken in collaboration with the Buccleuch Living Heritage Trust and the University of Cambridge (Faculty of History of Art and Architecture). I am grateful for the support of the Duke of Buccleuch and Queensberry, the Buccleuch archivist Crispin Powell, my supervisor Jeremy Musson and advisor Adam Menuge. I thank Oliver Ford for editing, and my parents for their support.

\section{REFERENCES}

Docu-tools, 2016. https://www.docu-tools.com/wie-allesbegann/ (10 June 2017)

Docu-tools, 2017. https://www.docu-tools.com/?lang=en (10 June 2017).

Cornforth, J., 1970-71. Bougton House: Northamptonshire. In: Country Life, part 1-5, Vol. 148149.

Cornforth, J., 1971. The Making of the Boughton Landscape. In: Country Life, Vol. 149, pp. 536-39.

Cornforth, J., 1992a. Castles for a Georgian Duke. In: Country Life, Vol. 186, pp. 58-61.

Cornforth, J., 1992b. Boughton: Impressions and People. In: Murdoch, T. (ed.), Boughton House: The English Versailles. Faber and Faber Limited, London, pp. 12-31.
Heward, J., 1992. Architecture at Boughton prior to 1685. In Murdoch, T. (ed.), Boughton House: The English Versailles. Faber and Faber Limited, London, pp. 44-55.

Heward, J., and Taylor, R., 1996. The Country Houses of Northamptonshire. RCHME, Swindon, pp. 94-109.

Historic England, 2017. List Entry Summary for Boughton House, https://historicengland.org.uk/listing/the-list/listentry/1000375 (12 June 2017).

Musson, J., 2011. English Country House Interiors. Rizollo, London.

Murdoch, T. (ed.), 1992. Boughton House: The English Versailles. Farber and Farber, London.

Pevsner, N. \& Bailey, B., 2013. The Buildings of England: Northamptonshire. $3^{\text {rd }}$ edition. Yale University Press, New Haven and London. 